\title{
Stem cell potential remains unchanged
}

\author{
John A Kessler
}

Claims by Woo-Suk Hwang and colleagues that they had achieved efficient somatic cell nuclear transfer and nuclear reprogramming ('therapeutic cloning') with human cells were recently revealed to be fraudulent. Furthermore, the investigators apparently violated basic ethical rules regarding the collection of human oocytes. This scandal has been cited not only as a setback for scientific progress, but also as a negative comment about the ethics, and even the merits, of all research with human stem cells, and as an indictment of the scientific review process. It can be argued, however, that these events are more of a reflection on human frailty than on stem cell research or the scientific process.

Like art forgeries, financial swindles and political lies, scientific hoaxes are nothing new. History tells us that quests for fame, fortune and power lead some individuals to blur or ignore ethical constraints. Society appropriately expects its scientists and physicians to meet the highest standards, but inevitably these standards will not be met by every individual. Moreover, the scientific review process for journals is not designed to test the integrity of the authors, but instead focuses on the rigor and value of what is reported in a manuscript. Does this mean that the process is flawed? Ironically, the Woo-Suk Hwang scandal demonstrated that the overall scientific process works. The hoax was uncovered within a relatively short time, and the media were alerted by young Korean scientists. The subsequent heightened scrutiny by the scientific community made it clear that the claims were unsupportable. Even if the deception had not been uncovered in this way, it would have become apparent sooner or

\section{Although \\ therapeutic \\ cloning in \\ humans \\ remains \\ elusive, the \\ potential for \\ stem cell \\ biology to \\ revolutionize \\ medicine has \\ not diminished}

JA Kessler is the Boshes Professor of Neurology and Chairman of the Department of Neurology at Northwestern University Feinberg Medical School, Chicago, IL, USA, and an Advisory Board member of Nature Clinical Practice Neurology.

\section{Competing interests}

The author declared he has no competing interests.

www.nature.com/clinicalpractice doi:10.1038/ncpneuro0174 later when other researchers failed to replicate the results. This does not lessen the burden on journals to scrutinize scientific reports and data as carefully as possible; however, the general principle of science-that the truth will emerge-was upheld.

What is the net effect of these events on the field of stem cell biology, and on its future for medicine and neurology? This case has certainly highlighted the fact that somatic cell nuclear transfer with human cells is not a trivial technological exercise. Nevertheless, stem cell biologists largely agree that it is achievable, and that no lasting damage has been done to the field. As with similar scandals in the past, the main casualty seems to be public trust of science and medicine. When scientists falter, those who support scientific research are disappointed, and those who oppose it are given more ammunition. Like all scandals, it will fade from the headlines, but it will no doubt be periodically resurrected by opponents of stem cell research.

Although therapeutic cloning in humans remains elusive, the potential for stem cell biology to revolutionize medicine has not diminished. If the technical hurdles can be overcome, the neurology field in particular is set to benefit considerably. Neurological diseases such as spinal cord injury and Parkinson's disease are likely to be among the first disorders in which embryonic stem cell therapies are tested. By the time that the first successful embryonic stem cell therapy is reported, it is hoped that the temporary setback due to the actions of Woo-Suk Hwang and his colleagues will be largely forgotten. 